\title{
The Effect of Intermittent Hypoxic Exposure on Erythropoietic Response and Hematological Variables in Elite Athletes
}

\author{
Anna KASPERSKA ${ }^{1}$, Agnieszka ZEMBRON-LACNY ${ }^{2}$ \\ ${ }^{1}$ Poznan University of Physical Education, Faculty of Physical Culture in Gorzów Wielkopolski, \\ Poland, ${ }^{2}$ Department of Applied and Clinical Physiology, Faculty of Medicine and Health Sciences, \\ University of Zielona Gora, Poland
}

Received September 23, 2019

Accepted January 15, 2020

Epub Ahead of Print March 23, 2020

\section{Summary}

This study aimed to evaluate the changes in the erythropoietin level and hematological variables in wrestlers after intermittent hypoxic exposure (IHE). Twelve wrestlers were assigned into two groups: hypoxia (sports training combined with $I H E, n=6$ ) and control (sports training, $n=6$ ). An IHE was performed for 10 days, with one day off after 6 days, once a day for about an hour. The concentrations of hydrogen peroxide $\left(\mathrm{H}_{2} \mathrm{O}_{2}\right)$, nitric oxide (NO), vascular endothelial growth factor (VEGF) and erythropoietin (EPO), as well as total creatine kinase activity (CK) were measured. Also, the hematological markers ( $\mathrm{Hb}$-hemoglobin, $\mathrm{Ht}$ - hematocrit, RBC - red blood cell, WBC white blood cell, Ret - reticulocytes) were analyzed. The 6-day IHE caused an increase in the levels of $\mathrm{H}_{2} \mathrm{O}_{2}$, NO and VEGF. Similarly, the EPO level and WBC count reached the highest value after 6 days of IHE. The total Ret number increase constantly during 10 days of IHE. The hypoxia group showed a higher CK activity compared to the control. In conclusion, 10-day IHE in combination with wrestling training elevates levels of $\mathrm{H}_{2} \mathrm{O}_{2}, \mathrm{NO}$ and VEGF, and improves the oxygen transport capacity by the release of EPO and Ret in circulation.

\section{Key words}

Erythropoietin • Hypoxia • Nitric oxide • Reticulocytes • Athletes

\section{Corresponding author}

Kasperska Anna, Poznan University of Physical Education, Faculty of Physical Culture in Gorzów Wielkopolski, Estkowskiego 13, Gorzów Wielkopolski 66-400, Poland. E-mail: annakasperska.awf@gmail.com

\section{Introduction}

Intermittent hypoxic exposure (IHE) is a common method used by athletes, which can enhance physical performance by alternating short exposure to high hypoxia $\left(9-12 \% \mathrm{O}_{2}\right)$ and normoxia. So far, IHE is common in endurance, but rarely in combat sports, and the available literature is mostly concerning endurance athletes. IHE used in endurance disciplines was applied both at rest or during physical training at sea level, which significantly affects speed, endurance and anaerobic capacity. Although some studies have shown that IHE has no significant hematological influence (Hinckson et al. 2007, Hamlin and Hellemans 2007, Flaherty et al. 2016, Czuba et al. 2017). So far, we know that IHE at sea level has not only a significant effect on endurance and anaerobic ability but also contributes to faster adaptation to low and moderate heights ( $<2500$ meters) (Gore 2006, Hinckson et al. 2007, Hamlin and Hellemans, 2007). However, it should be remembered that IHE is an additional load to the organism and may pose some health risk, hence the need for rest after hypoxic training sessions (Schommer et al. 2012). Hypoxia, as well as sports training, leads to skeletal muscle damage. The regeneration of skeletal muscle in individuals performing physical training requires the participation of several molecules including VEGF (vascular endothelial growth factor), EPO (erythropoietin) and RONS (reactive oxygen and nitrogen species) - mainly $\mathrm{H}_{2} \mathrm{O}_{2}$ (hydrogen peroxide) and NO (nitric oxide) (Wilber et al. 2007). The production of $\mathrm{H}_{2} \mathrm{O}_{2}$ and $\mathrm{NO}$ in tissues can be modulated 
by exercise and hypobaric hypoxia in the form of altitude training or normobaric hypoxia. Even a small increase in the concentration of NO activates the hypoxia-inducible factor 1 (HIF-1) and stimulates the release of VEGF and EPO (Kimura and Esumi 2003, Filippin et al. 2009, Wilber et al. 2007). To adapt to the hypoxic conditions, the human body has developed the ability to cope with low oxygen levels through cardiovascular reactions, increased the oxidative capacity in muscles, increased minute ventilation and the release of HIF (hypoxiainducible factor), which regulates the expression of about 100 genes (De Smet et al. 2017, Boos et al. 2018). Likewise, an adaptation of the human organism in exposure to hypoxia is characterized by an increase in hemoglobin and hematocrit levels, which increase the ability of the blood to carry oxygen and improve respiratory function (Hoppeler and Vogt 2001, Wilber et al. 2007, De Smet et al. 2017).

Therefore, the study aimed to analyze modifications of erythropoietic and hematological parameters after 10 days of IHE, compared to normoxic training in highly trained Greco-Roman wrestlers.

\section{Methods}

Twelve male Greco-Roman wrestlers, members of the Polish national team (Table 1), were observed during the preparatory training period in the National Olympic Sports Centre. Wrestlers were randomly divided into two groups: the hypoxia group ( $n=6,22.8 \pm 2.6 \mathrm{yr}$ ), IHE combine with sports training in normoxia and the control group ( $n=6,24.7 \pm 3.4 \mathrm{yr}$ ) participating in usual sport training. During the sports camp, all athletes lived in the same accommodation, followed the same training schedule and diet. The sport training loads were demonstrated using the training program (Training 1.2., TREOB4, Department of Sports Theory, University School of Physical Education Warsaw, Poland). The training protocol comprise three types of training. Comprehensive training included: team games, marches and cross-country running, cross-country skiing, acrobatic exercises, climbing at ropes, pull-ups, exercises with partner and it was on $55 \%$ of total training load. Directed training was on $9 \%$ of total training load: intervals, toss from knees, back suplex, reverse waist, turns. Special/wrestling training: elevation from the low position, keys, trolleys, throws with a different amplitude of movement, gym was on $25 \%$ of total training load. All the subjects were informed of the aim of the study gave their written consent for participation in the project. The protocol of the study was approved by the ethics committee at the Medical University Poznan (No. 550/11), in accordance with the Declaration of Helsinki.

Table 1. Anthropometric characteristics of hypoxia and control group.

\begin{tabular}{|c|c|c|c|}
\hline Variables & before IHE & after $6 \mathrm{~d}$ IHE & after $10 \mathrm{~d}$ IHE \\
\hline \multicolumn{4}{|c|}{ Height (cm) } \\
\hline control & $171.3 \pm 6.0$ & & \\
\hline hypoxia & $181.2 \pm 7.3$ & & \\
\hline \multicolumn{4}{|l|}{ Weight (kg) } \\
\hline control & $73.8 \pm 9.7$ & $74.9 \pm 10.1$ & $75.0 \pm 10.1$ \\
\hline hypoxia & $97.1 \pm 22.7$ & $98.5 \pm 22.4$ & $98.6 \pm 21.9$ \\
\hline \multicolumn{4}{|c|}{$B M I\left(\mathrm{~kg} / \mathrm{m}^{2}\right)$} \\
\hline control & $25.1 \pm 2.1$ & $25.4 \pm 2.2$ & $25.5 \pm 2.2$ \\
\hline hypoxia & $29.3 \pm 5.2$ & $29.8 \pm 5.1$ & $29.8 \pm 5.0$ \\
\hline \multicolumn{4}{|l|}{$F M \%$} \\
\hline control & $8.9 \pm 3.4$ & $8.9 \pm 3.6$ & $7.8 \pm 2.8$ \\
\hline hypoxia & $14.5 \pm 6.0$ & $13.7 \pm 7.5$ & $12.7 \pm 6.8$ \\
\hline \multicolumn{4}{|l|}{$F M(\mathrm{~kg})$} \\
\hline control & $6.5 \pm 2.7$ & $6.6 \pm 2.7$ & $5.8 \pm 2.2$ \\
\hline hypoxia & $15.1 \pm 9.5$ & $14.9 \pm 11.0$ & $13.7 \pm 10.1$ \\
\hline \multicolumn{4}{|l|}{$F F M(\mathrm{~kg})$} \\
\hline control & $67.3 \pm 2.7$ & $68.2 \pm 10.0$ & $69.2 \pm 9.7$ \\
\hline hypoxia & $81.9 \pm 14.0$ & $83.7 \pm 12.0$ & $84.9 \pm 12.8$ \\
\hline
\end{tabular}


Body mass and composition (free fat mass FFM, fat mass - FM) were evaluated using the impedance technique (Analyzer Tanita MC-418, Japan), calibrated before each test session following the manufacturer's guidelines. Duplicate measures were taken with the participant in a standing position; the average value was used for the final analysis. The recurrence of the measurement amounted to $98 \%$. The measurements were taken between 7.00 and 8.00 a.m. before blood sampling and breakfast.

The passive 6-day IHE was conducted under medical supervision using the $\mathrm{GO}_{2}$ Altitude Hypoxicator Australia $\left(\mathrm{FiO}_{2}\right.$ - Fraction of Inspired Oxygen $=9-15 \%$; 2,500 to 6,500 meters above sea level), in the fourposition version, according to the procedure described by Hinckson et al. (2007). The IHE consisted of 6 days of IHE, a day off and consecutive 4 days of IHE (Fig. 1). The restitution (day off) was planned for both the groups. IHE was held once a day, for about an hour, in the evening, at least two hours after sport training, for 10 days. The athletes received alternate hypoxic and normoxic breaths through a face mask, $\mathrm{FiO}_{2}=$ approximately $14 \%-12 \%$, which simulated the height of approximately 2,500-4,500 meters above sea level. The time of the hypoxic dose was 3-8 minutes, and the breaks took 3-5 min. One IHE session consisted of 6 doses of hypoxic and normoxic intervals per day. IHE started with two sessions of acclimatization with the oxygen concentration in the mask $\mathrm{FiO}_{2}=13.5 \%$ (equivalent to approximately 3,000 m). Then, the proper IHE sessions were used to increase the height until the athlete reached an oxygen concentration of $\mathrm{FiO}_{2}=12 \%$ (equivalent to approximately $4,500 \mathrm{~m}$ above sea level) and was subsequently $\mathrm{FiO}_{2}=13 \%$ for two sessions, $\mathrm{FiO}_{2}=12.5 \%$ for two sessions, day off, another two sessions $\mathrm{FiO}_{2}=12.5 \%$ and at the end two sessions $\mathrm{FiO}_{2}=12 \%$ (Fig. 1). While at each IHE session, the blood saturation $\left(\mathrm{SpO}_{2}\right)$ and heart rate $(\mathrm{HR})$ were monitored.

Blood samples were taken from the antecubital vein between 7.00 and 8.00 a.m., on an empty stomach, before the first session of the IHE, after 6 days and after 10 days of IHE sessions (Fig. 1). Within $20 \mathrm{~min}$, the blood samples were centrifuged at $3000 \mathrm{~g}$ and $+4{ }^{\circ} \mathrm{C}$ for $10 \mathrm{~min}$. Aliquots of the serum were stored at $-80^{\circ} \mathrm{C}$.

Serum total creatine kinase (CK) activity was evaluated using commercially available reagents and the Dr Lange analyzer (Germany) at a temperature of $20-25{ }^{\circ} \mathrm{C}$.

Serum hydrogen peroxide $\left(\mathrm{H}_{2} \mathrm{O}_{2}\right)$ and nitric oxide (NO) concentrations were determined using the Oxis
Research kit (USA). $\mathrm{H}_{2} \mathrm{O}_{2}$ and $\mathrm{NO}$ detection limits were $6.25 \mu \mathrm{mol} / 1$ and $0.5 \mu \mathrm{mol} / 1$, respectively. The intra-assay coefficient of variation for the $\mathrm{H}_{2} \mathrm{O}_{2}$ and $\mathrm{NO}$ was $<5 \%$. Serum erythropoietin (EPO) and vascular endothelial growth factor (VEGF) levels were determined by enzyme immunoassay methods using commercial kits from R\&D Systems (USA). The detection limits for EPO and VEGF were $5.0 \mathrm{pg} / 1$ and $0.6 \mathrm{mlU} / \mathrm{ml}$, respectively. The average intra-assay coefficient of variation for the EPO and VEGF was $<8.0 \%$. The hematological markers ( $\mathrm{Hb}, \mathrm{Ht}, \mathrm{RBC}$, WBC and Ret) were determined by professional laboratory company Diagnostyka (Poland, ISO 15189).

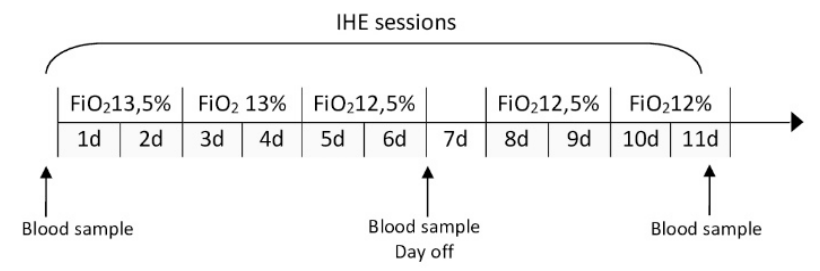

Fig. 1. The intermittent hypoxic exposure (IHE) and blood sampling during a sports camp.

Statistical calculations were performed using the Statistica 13.1 software (StatSoft Inc., Tulsa, OK, USA). All data were tested for normality distribution using the Shapiro-Wilk test. The values of $\mathrm{W}$ for the biochemical markers were close to one; therefore, the statistical significances were assessed using a one-way analysis of variance (ANOVA) and a posthoc test (HSD Tukey). Associations among the measured parameters were analyzed using Pearson's linear regression (r coefficient). The statistical significance was set at $P<0.05$. The results were expressed as the mean and standard deviation $(\mathrm{x} \pm \mathrm{SD})$.

\section{Results}

After the 6 days of IHE, the $\mathrm{H}_{2} \mathrm{O}_{2}$ level increased almost 1.5-fold higher, compared to baseline and control group, whereas, a day off and a further 4 days of IHE caused a decrease nearly to baseline. Similarly, the NO concentration increased significantly after 6 days of IHE, and after the recovery day and the consecutive 4 days of IHE, the concentration of NO was 1.5-fold higher than the baseline when compared to control group (Table 2).

The level of VEGF was significantly higher after 6 days of IHE (Table 2). In addition, 6 days of IHE caused almost a 2-fold higher level of VEGF in the hypoxia group when compared to the control group. 
Table 2. Changes in hydrogen peroxide (H2O2), nitric oxide (NO), vascular endothelial growth factor (VEGF), hematological variables and erythropoietin (EPO) level before and after the intermittent hypoxic exposure (IHE).

\begin{tabular}{|c|c|c|c|c|c|}
\hline Variables & before IHE & after $6 \mathrm{~d} I \mathrm{IHE}$ & $\begin{array}{c}\text { control vs. } \\
\text { hypoxia }\end{array}$ & after $10 \mathrm{~d} I H E$ & $\begin{array}{c}\text { control vs. } \\
\text { hypoxia }\end{array}$ \\
\hline \multicolumn{6}{|l|}{$\mathrm{H}_{2} \mathrm{O}_{2} \mu \mathrm{mol} / \mathrm{l}$} \\
\hline Control & $28.7 \pm 1.4$ & $38.0 \pm 3.9 * * *$ & \multirow{2}{*}{$P>0.05$} & $29.0 \pm 3.8$ & \multirow{2}{*}{$P>0.05$} \\
\hline Hypoxia & $29.3 \pm 1.8$ & $40.4 \pm 4.6^{* * *}$ & & $30.9 \pm 4.8$ & \\
\hline \multicolumn{6}{|l|}{ NO $\mu \mathrm{mol} / \mathrm{l}$} \\
\hline Control & $13.9 \pm 0.5$ & $15.3 \pm 0.5^{*}$ & \multirow[t]{2}{*}{$P<0.01$} & $15.7 \pm 0.84 * *$ & \multirow[t]{2}{*}{$P<0.01$} \\
\hline Hypoxia & $14.8 \pm 0.8$ & $18.7 \pm 0.7^{* *}$ & & $22.3 \pm 0.9 * * *$ & \\
\hline \multicolumn{6}{|l|}{$V E G F \mathrm{pg} / \mathrm{ml}$} \\
\hline Control & $213 \pm 71$ & $183 \pm 70$ & \multirow[t]{2}{*}{$P<0.05$} & $222 \pm 49$ & \multirow[t]{2}{*}{$P<0.01$} \\
\hline Hypoxia & $245 \pm 54$ & $339 \pm 59 * *$ & & $350 \pm 68 * * *$ & \\
\hline \multicolumn{6}{|l|}{ EPO $\mathrm{mIU} / \mathrm{ml}$} \\
\hline Control & $2.5 \pm 0.7$ & $3.6 \pm 0.7^{*}$ & \multirow[t]{2}{*}{$P<0.001$} & $4.2 \pm 0.4 * * *$ & \multirow[t]{2}{*}{$P<0.001$} \\
\hline Hypoxia & $2.3 \pm 0.3$ & $9.7 \pm 2.3 * * *$ & & $6.6 \pm 0.7 * *$ & \\
\hline \multicolumn{6}{|l|}{$\mathrm{Hbg} / \mathrm{dl}$} \\
\hline Control & $15.6 \pm 0.2$ & $15.6 \pm 0.6$ & \multirow[t]{2}{*}{$P>0.05$} & $14.3 \pm 0.7 * * *$ & \multirow[t]{2}{*}{$P>0.05$} \\
\hline Hypoxia & $15.1 \pm 0.8$ & $14.4 \pm 1.0$ & & $14.3 \pm 0.6$ & \\
\hline \multicolumn{6}{|l|}{$\mathrm{Ht} \%$} \\
\hline Control & $45.9 \pm 1.2$ & $44.2 \pm 1.8$ & \multirow[t]{2}{*}{$P>0.05$} & $43.4 \pm 1.8 *$ & \multirow[t]{2}{*}{$P>0.05$} \\
\hline Hypoxia & $45.7 \pm 1.1$ & $45.1 \pm 2.4$ & & $44.2 \pm 2.4$ & \\
\hline \multicolumn{6}{|l|}{$R B C \mathrm{mln} / \mathrm{mm}^{3}$} \\
\hline Control & $5.5 \pm 0.2$ & $5.0 \pm 0.3 * *$ & \multirow[t]{2}{*}{$P>0.05$} & $4.7 \pm 0.2 * * *$ & \multirow[t]{2}{*}{$P>0.05$} \\
\hline Hypoxia & $5.2 \pm 0.4$ & $5.0 \pm 0.5$ & & $4.7 \pm 0.3 * *$ & \\
\hline \multicolumn{6}{|l|}{$W B C 10^{3} / \mu l$} \\
\hline Control & $5.2 \pm 0.5$ & $5.3 \pm 0.7$ & \multirow[t]{2}{*}{$P<0.001$} & $6.1 \pm 0.3 *$ & \multirow[t]{2}{*}{$P>0.05$} \\
\hline Hyрохіа & $6.0 \pm 0.5$ & $7.1 \pm 0.5 *$ & & $6.7 \pm 0.8$ & \\
\hline \multicolumn{6}{|l|}{ Ret \%o } \\
\hline Control & $4.0 \pm 1.3$ & $4.8 \pm 1.5$ & \multirow[t]{2}{*}{$P<0.01$} & $10.3 \pm 2.1 * * *$ & \multirow[t]{2}{*}{$P<0.001$} \\
\hline Hypoxia & $3.0 \pm 0.6$ & $8.7 \pm 2.5^{* *}$ & & $13.5 \pm 2.3 * * *$ & \\
\hline
\end{tabular}

The concentration of VEGF has grown constantly during the 10-day IHE and was almost 1.5-fold higher when compared to the baseline and control group.

During the 10-day intermittent hypoxic exposure, there were no significant differences in the $\mathrm{Hb}$ and $\mathrm{Ht}$ levels in the hypoxia group. While there was a significant increase in the EPO concentration and WBC in the hypoxia group (Table 2). The EPO and WBC concentration reached the highest values after 6 days of IHE, but after restitution and a further 4 days, the IHE decreased. However, after the 10-day IHE, the EPO and WBC level remained at a higher level when compared to baseline. After 10 days of IHE, the hypoxia group showed almost a 3-fold higher EPO level when compared to baseline. The control group was characterized by the constant increase in the EPO and WBC level, but it was not as high as the values in the hypoxia group. In contrast, the concentration of RBC was similar in both groups, and it was constantly declining during the sports camp. The Ret number increased 3-fold after 6 days of IHE and 4.5-fold after the 10-day IHE. In the control group, the Ret number did not change significantly after 6-days of wrestling training, but after the 10-day training programme it increased 2.5-fold when compared to the 
baseline (Table 2).

The hypoxia group was characterized by the intensifying muscle damage demonstrated by a significantly higher level of the total CK activity while whole IHE when compared to the control group (Fig. 2). After the 6 days of IHE, the CK activity significantly increased to $539 \pm 68 \mathrm{IU} / 1$, while in the control increased to $313 \pm 91 \mathrm{IU} / 1$. After the recovery day and a further 4 days of IHE, the CK activity increased to $975 \pm 173 \mathrm{IU} / \mathrm{l}$, whereas in the control group it increased to $555 \pm 151 \mathrm{IU} / 1$ (Fig. 2). Finally, the total CK activity increased by over 5 -fold after the 10-day IHE, whereas in the control group, the CK activity increased 3-fold when compared to the baseline levels.

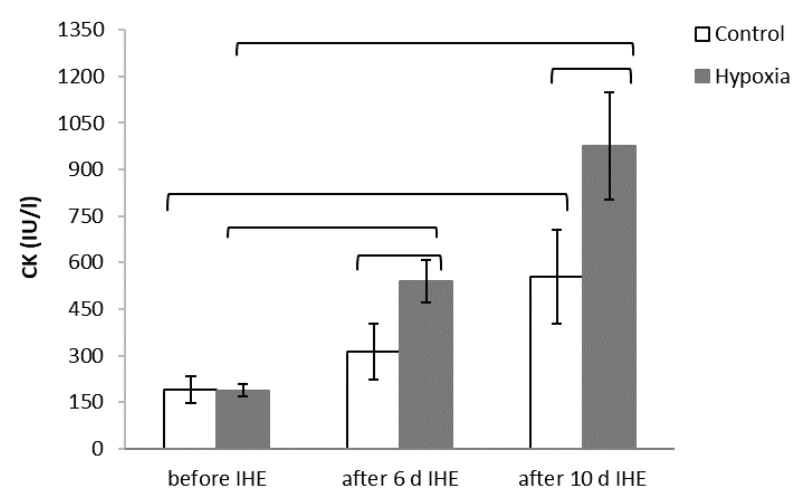

Fig. 2. Changes in total creatine kinase (CK) during sports camp; statistically significant differences in the hypoxia and control group compared to baseline (before IHE). Significant differences: $* \mathrm{P}<0.05 ; * * * \mathrm{P}<0.001$.

\section{Discussion}

So far, most of the studies concerning IHE efficiency at sea level have been carried out focusing on the impact of IHE on the endurance tests (Millet $e t$ al. 2014). According to Hoppeler and Vogt (2001), a few hours of mild IHE through changes in energy and metabolism regulators and also hematologic responses may be complementary to training programs in order to increase the aerobic capacity and muscle adaptation to exercise. Our study showed a continuous increase in the $\mathrm{CK}$ activity in the hypoxia group when compared to the control. The highest CK activity in the hypoxia group was observed after 10 days of IHE, and it was $40 \%$ higher than in the control group. Therefore, it is relevant that the IHE is an additional load for skeletal muscle and including it in intensive, strength sports training may have a negative effect on the repair process and increase the risk of non-functional fatigue or overtraining in athletes. The inability to acclimatize or reaching high altitude too quickly leads to serious consequences. These illnesses are acute mountain suckness (AMS), highaltitude pulmonary edema (HAPE) and high-altitude cerebral edema (HACE) (Paralikar and Paralikar 2010). This means that IHE should be used with moderate exercise. According to Gatterer et al. (2013), an hourlong session of normobaric hypoxia $\left(\mathrm{FiO}_{2} \quad 13.5 \%\right.$ approximately $4000 \mathrm{~m}$ ) had no effect on changes in the CK activity during football rehabilitation. Additionally, hypoxia is used to induce adaptation in skeletal muscle. Although, acute exposure to hypoxia at an altitude of 4,300 $\mathrm{m}$ may increase muscle lactate production, glycogenolysis, glycolysis and a reduction in muscle mass (Vargas-Pinilla 2014).

According to the literature, high altitude stimulates RONS generation by increasing the flow of electrons and protons in the respiratory chain, increasing oxidase activity, nitric oxide synthase (iNOS) and reducing the effectiveness of the antioxidant defence. Moreover, the generation of RONS enhances the cell damage through the peroxidation of lipids, proteins and DNA, what induces muscle fibre damage and increased CK (Bakonyi and Radak 2004, Michalczyk et al. 2016). Also, hypoxia can reduce the antioxidant capacity of the body, which effects in an increase in oxidative stress and the occurrence of fatigue (Poprzecki et al. 2016). The present study showed a significant increase in the $\mathrm{H}_{2} \mathrm{O}_{2}$ and $\mathrm{NO}$ concentration. The highest value of $\mathrm{H}_{2} \mathrm{O}_{2}$ was observed after 6 days of IHE, while the 10-day IHE showed an increase in NO. Wahl et al. (2013) observed that short-term hypoxia in combination with low-intensity training stimulates the production of angiogenic factors, which is responsible for the development of blood vessels and improved endurance. In the present study, we observed constantly increased VEGF levels during IHE, and its values were higher when compared to the control group. The 10-day IHE increased the VEGF level by 1.5 -fold, while in the control group, no significant difference was found. Likewise, Wahl et al. (2013) reported a significant VEGF increase after normobaric hypoxia for $90 \mathrm{~min}, 4000 \mathrm{~m}\left(13.2 \% \mathrm{O}_{2}\right)$.

Short-term hypobaric and normobaric hypoxia exposure stimulates EPO production and increases Ret, $\mathrm{Hb}$ and $\mathrm{Ht}$ values in athletes and non-athletes (Levine 2002, Basset et al. 2006). The results of our study did not show any significant changes in the $\mathrm{Hb}$ and $\mathrm{Ht}$ levels under hypoxia exposure. Earlier, similar observations 
were made by Katayama et al. (2003), using 90 min of hypoxia, 3 times a day for 3 weeks. Moreover, no changes in the hematologic responses were demonstrated by Gore et al. (2006), who exposed swimmers and runners to 4-week hypobaric hypoxia. Furthermore, Hinckson et al. (2007) found no changes after exposing rugby players to 14 days of IHE, Pupis and Cillik (2008) found no difference after exposing walkers to 3-8 weeks of IHE.

In response to hypoxia, the concentration of EPO increases by erythropoiesis, which increases the number of Ret. Moreover, acute hypoxia can cause an increase in the Ret number, increasing the release of immature red blood cells from bone marrow without accelerating proper erythropoiesis (Garcia et al. 2000, Julian et al. 2004). In our study, the Ret number significantly increased after 6- and 10 days of IHE when compared to the baseline and control group. Similar observations were made by Julian et al. (2004) using a 9-day IHE (2 hours per day, $5000 \mathrm{~m}$ ) and Garcia et al. (2000) using a 5-day IHE (2 hours per day, $3800 \mathrm{~m}$ ). High EPO levels have a positive effect on muscle regeneration due to its antioxidant and anti-apoptotic properties (Gatterer et al. 2013). Joyeux-Faure (2007) have suggested that EPO stimulates tissue repair after various injuries, through the recruitment of vascular endothelial progenitor cells. That's why hypoxia through increased synthesis and the release of EPO may affect post-effort regeneration (Joyeux-Faure 2007). In the present study, the 6-day IHE resulted in an over 4-fold significant increase in the EPO concentrations. After a day off and another 4 days of IHE, the EPO concentration decreased, but it was still 3-fold higher than in the control group. Gatterer et al. (2013) and Wahl et al. (2013) showed that a single 80-90 min hypoxia session $(4000 \mathrm{~m})$ induces a $67 \%$ increase in the EPO concentration. Previous research by Gore et al. (2006) has shown that the change of the altitude level from 4000 to $5500 \mathrm{~m}$ (80-90 min hypoxia) induces a 2-fold increase in EPO production. Extending the hypoxia time to 3 hours causes a further increase in the EPO concentration. Abellan et al. (2005), using similar hypoxia conditions (4000-5500 $\mathrm{m}$ above sea level, 3 hours per day), observed a 4-fold increase in the EPO concentration. Friedmann et al. (2005), using mild hypoxia $(2500 \mathrm{~m})$, showed an increase in the concentration of EPO in the swimmers.

In conclusion, the most important findings of this study indicate that wrestling training conducted with intermittent hypoxic exposure during the first 6 days increased the RONS, VEGF, EPO, Ret, WBC and CK levels. These data suggest that even short IHE is an effective method to improve erythropoiesis and angiogenesis, which in turn can affect the athlete's adaptation to both hypoxia and intense exercise.

\section{Conflict of Interest}

There is no conflict of interest.

\section{Acknowledgements}

We would like to thank the coaches and the team of wrestlers participating in the study. The study was supported by the National Science Centre under Grant 2011/01/N/NZ7/05282.

\section{References}

ABELLAN R, REMACHA AF, VENTURA R, SARDA MP, SEGURA J, REDRIGUEZ FA: Hematologic response to four weeks of intermittent hypobaric hypoxia in highly trained athletes. Hematologica 90: 126-127, 2005.

BAKONYI T, RADAK Z: High altitude and free radicals. J Sports Sci Med 3: 64-69, 2004.

BASSET FA, JOANISSE DR, BOIVIN F, ST-ONGE J, BILLAUT F, DORE J, R CHOUINARD, G FALGAIRETTE, D RICHARD, BOULAY MR: Effects of short-term normobaric hypoxia on haematology, muscle phenotypes and physical performance in highly trained athletes. Exp Physiol 91: 391-402, 2006. https://doi.org/10.1113/expphysiol.2005.031682

BOOS CJ, LAMB CM, MIDWINTER M, MELLOR A, WOODS DR, HOWLEY M, STANSFIELD T, FOSTER M, O'HARA JP: The effects of acute hypoxia on tissue oxygenation and circulating alarmins in healthy adults. Physiol Res 67: 935-943, 2018. https://doi.org/10.33549/physiolres.933743

CZUBA M, WILK R, KARPIŃSKI J, CHALIMONIUK M, ZAJĄC A, LANGFORT J: Intermittent hypoxic training improves anaerobic performance in competitive swimmers when implemented into a direct competition mesocycle. PLOS ONE, 2017. https://doi.org/10.1371/journal.pone.0180380 
DE SMET S, VAN HERPT P, D'HULST G, VAN THIENEN R, VAN LEEMPUTTE M, HESPEL P: Physiological adaptations to hypoxic vs. normoxic training during Intermittent living high. Front Physiol 8: 347, 2017. https://doi.org/10.3389/fphys.2017.00347

FILIPPIN LI, MOREIRA AJ, MARRONI NP, XAVIER RM: Nitric oxide and repair of skeletal muscle injury. Nitric Oxide 21: 157-163, 2009. https://doi.org/10.1016/j.niox.2009.08.002

FLAHERTY G, O'CONNOR R, JOHNSTON N: Altitude training for elite endurance athletes: A review for the travel medicine practitioner. Travel Med Infect Dis 14: 200-211, 2016. https://doi.org/10.1016/j.tmaid.2016.03.015

FRIEDMANN B, FRESE F, MENOLD E, KAUPER F, JOST J, BARTSCH P: Individual variation in the erythropoietic response to altitude training in elite junior swimmers. Br J Sports Med 39: 148-153, 2005. https://doi.org/10.1136/bjsm.2003.011387

GARCIA N, HOPKINS SR, POWELL FL: Intermittent vs continuous hypoxia: effects on ventilation and erythropoiesis in humans. Wilderness Environ Med 11: 172-179, 2000. https://doi.org/10.1580/10806032(2000)011[0172:IVCHEO]2.3.CO;2

GATTERER H, SCHENK K, WILLE M, MURNIG P, BURTSCHER M: Effects of massage under hypoxic conditions on exercise-induced muscle damage and physical strain indices in professional soccer players. Biol Sport 30 : 81-83, 2013. https://doi.org/10.5604/20831862.1044221

GORE CHJ, RODRIGUEZ FA, TRUIJENS MJ, TOWNSEND NE, STRAY-GUNDERSEN J, LEVINE BD: Increased serum erythropoietin but not red cell production after 4 weeks of intermittent hypobaric hypoxia (4,000-5,500 m). J Appl Physiol 101: 1386-1393, 2006. https://doi.org/10.1152/japplphysiol.00342.2006

HAMLIN MJ, HELLEMANS J: Effect of intermittent normobaric hypoxic exposure at rest on hematological, physiological, and performance parameters in multi-sport athletes. J Sports Sci 25: 431-441, 2007. https://doi.org/10.1080/02640410600718129

HINCKSON EA, HAMLIN MJ, WOOD MR, HOPKINS WG: Game performance and intermittent hypoxic training. Br J Sports Med 41: 537-539, 2007. https://doi.org/10.1136/bjsm.2006.033712

HOPPELER H, VOGT M: Muscle tissue adaptations to hypoxia. J Exp Biol 204: 3133-3139, 2001.

JOYEUX-FAURE MJ: Cellular protection by erythropoietin: new therapeutic implications? J Pharmacol Exp Ther 323 : 759-762, 2007. https://doi.org/10.1124/jpet.107.127357

JULIAN CG, GORE CHJ, WILBER RL, DANIELS JT, FREDERICSON M, STRAY-GUNDERSEN J, HAHN AG, PARISOTTO R, LEVINE BD: Intermittent normobaric hypoxia does not alter performance or erythropoietic markers in highly trained distance runners. J Appl Physiol 96: 1800-1807, 2004. https://doi.org/10.1152/japplphysiol.00969.2003

KATAYAMA K, MATSUO H, ISHIDA K, MORI S, MIYAMURA M: Intermittent hypoxia improves endurance performance and sumaximal exercise efficiency. High Alt Med Biol 3: 291-304, 2003. https://doi.org/10.1089/152702903769192250

KIMURA H, ESUMI H: Reciprocal regulation between nitric oxide and vascular endothelial growth factor in angiogenesis. Acta Biochim Polonica 50: 49-59, 2003. https://doi.org/10.18388/abp.2003 3713

LEVINE BD: Intermittent hypoxic training: fact and fancy. High Alt Med Biol 3: 177-193, 2002. https://doi.org/10.1089/15270290260131911

MICHALCZYK M, CZUBA M, ZYDEK G, ZAJĄC A, LANGFORT J: Dietary recommendations for cyclists during altitude training. Nutrients 8: 377, 2016. https://doi.org/10.3390/nu8060377

MiLleT G, BENTLEY DJ, ROELS B, MCNAUGHTON LR, MERCIER J, CAMERON-SMITH D: Effects of intermittent training on anaerobic performance and MCT transporters in athletes. PLoS ONE 9: e95092, 2014. https://doi.org/10.1371/journal.pone.0095092

PARALIKAR SJ, PARALIKAR JH: High-altitude medicine. Indian J Occup Environ Med 14: 6-12, 2010. https://doi.org/10.4103/0019-5278.64608

POPRZECKI S, CZUBA M, ZAJĄC A, KARPIŃSKI J, WILK R, BRIL G, MASZCZYK A, TOBOREK M: The blood antioxidant defence capacity during intermittent hypoxic training in elite swimmers. Biol Sport 33: 353-360, 2016. https://doi.org/10.5604/20831862.1221607

PUPIS M, CILLIK I: The influence of intermittent hypoxic training on the body of an endurance athlete. Facta Universitatis. Phys Educ Sport 6: 11-20, 2008. 
SCHOMMER K, MENOLD E, SUBUDHI AW, BÄRTSCH P: Health risk for athletes at moderate altitude and normobaric hypoxia. Br J Sports Med 46: 828-832, 2012. https://doi.org/10.1136/bjsports-2012-091270

VARGAS-PINILLA OC: Exercise and training at altitudes: physiological effects and protocols. Rev Cienc Salud 12: 111-126, 2014. https://doi.org/10.12804/revsalud12.1.2014.07

WAHL P, SCHMID A, DEMAREES M, ACHTZEHN S, BLOCH W, MESTER J: Responses of angiogenic growth factors to exercise, to hypoxia and to exercise under hypoxic conditions. Int J Sport Med 34: 95-100, 2013. https://doi.org/10.1055/s-0032-1314815

WILBER RL, STRAY-GUNDERSEN J, LEVINE BD: Effect of hypoxic "dose" on physiological responses and $\begin{array}{lllllll}\text { sea-level performance. } & \text { Med Sci } & \text { Sports }\end{array}$ https://doi.org/10.1249/mss.0b013e3180de49bd 